\title{
Eu e Meu Guarda-chuva. Medo de quê? Ou quando a aventura pode estar na possibilidade de conhecer
}

Maria Ignês Carlos Magno

Doutora em Ciências da Comunicação pela ECA/USP.

Professora do mestrado em Comunicação da Universidade Anhembi Morumbi e da Fundação Escola de Sociologia e Política de São Paulo.

E-mail: unsigster@gmail.com

Resumo: A videografia deste número traz o filme Eu e Meu Guarda-chuva (2010), de Toni Vanzolini, baseado na obra homônima de Branco Mello, Hugo Possolo e Ciro Pessoa. As afirmações e perguntas que o filme apresenta são um excelente exercício para a sala de aula, já que o cinema é um meio que convida e favorece a imaginação e a construção de sensibilidades.

Palavras-chave: Eu e Meu Guarda-chuva, cinema, escola, memória, educação.
Abstract: This issue's Videograghy brings the motion picture Eu e Meu Guarda-chuva [Me and my umbrella] (2010) by Toni Vanzolini, based on the homonymous work by Branco Mello, Hugo Possolo and Ciro Pessoa. Statements and questions brought by the picture are an excellent exercise to classroom, once that cinema is a media that invites and favors imagination and the construction of sensibilities.

Keywords: Eu e Meu Guarda-chuva, cinema, school, memory, education.

O filme Eu e Meu Guarda-chuva (2010), de Toni Vanzolini, baseado na obra homônima de Branco Mello, Hugo Possolo e Ciro Pessoa, começa com uma afirmação e muitas perguntas. A afirmação escrita na página inicial de um livro sobre a Grécia é a de que existir é ser prisioneiro da terra e as perguntas, as tantas perguntas que conduzem à narrativa, ficam por conta do Barão Von Staffen e das crianças protagonistas da história. Do Barão ficamos sabendo que, por odiar burrices, submetia as crianças a intermináveis sabatinas sobre geografia, história, botânica, verbos, até o dia em que caiu morto diante de uma delas, porque não soube responder a nenhuma de suas perguntas. Fantasma na própria escola que fundou, continuava, segundo a lenda, a atormentar as crianças com suas perguntas. 
Dos protagonistas sabemos que vivem uma aventura no último dia de férias e a expectativa de iniciar uma nova fase da vida escolar: entrar para o sexto ano no Colégio Von Staffen. Na adaptação do livro infantil, o filme conta a história de Eugênio, Cebola e Frida, que, na ânsia de saberem como era a nova escola, se envolvem com o temível fantasma Von Staffen. No sonho, Frida é feita prisioneira do barão e Eugênio e Cebola fazem de tudo para libertar a amiga e primeira paixão de Eugênio. $\mathrm{Na}$ aventura, a única arma de que dispõem é um guarda-chuva. Não qualquer guarda-chuva, mas o herdado de seu avô contador de histórias e ponte entre gerações e conhecimentos. Pela fotografia dos avós em Paris, Eugênio fica sabendo, ao ler

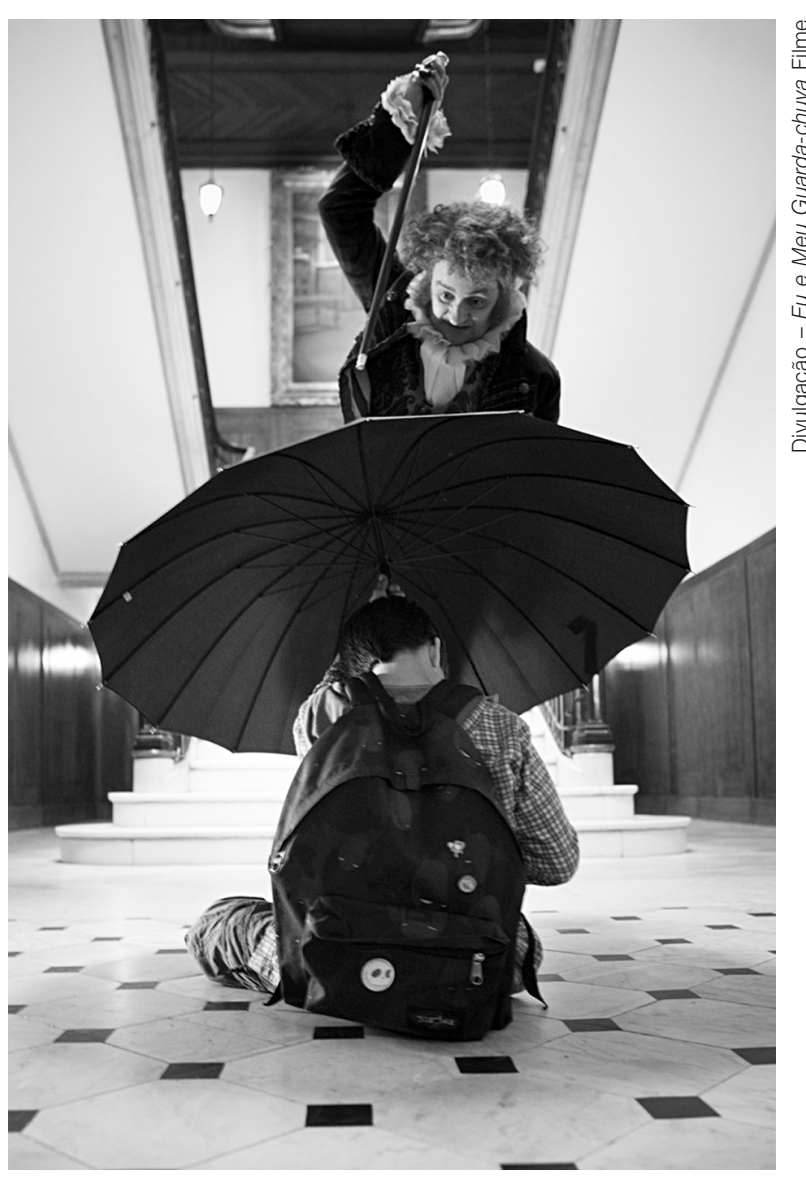

Barão Von Staffen e Eugênio. no verso da foto, que somos feitos de memória.

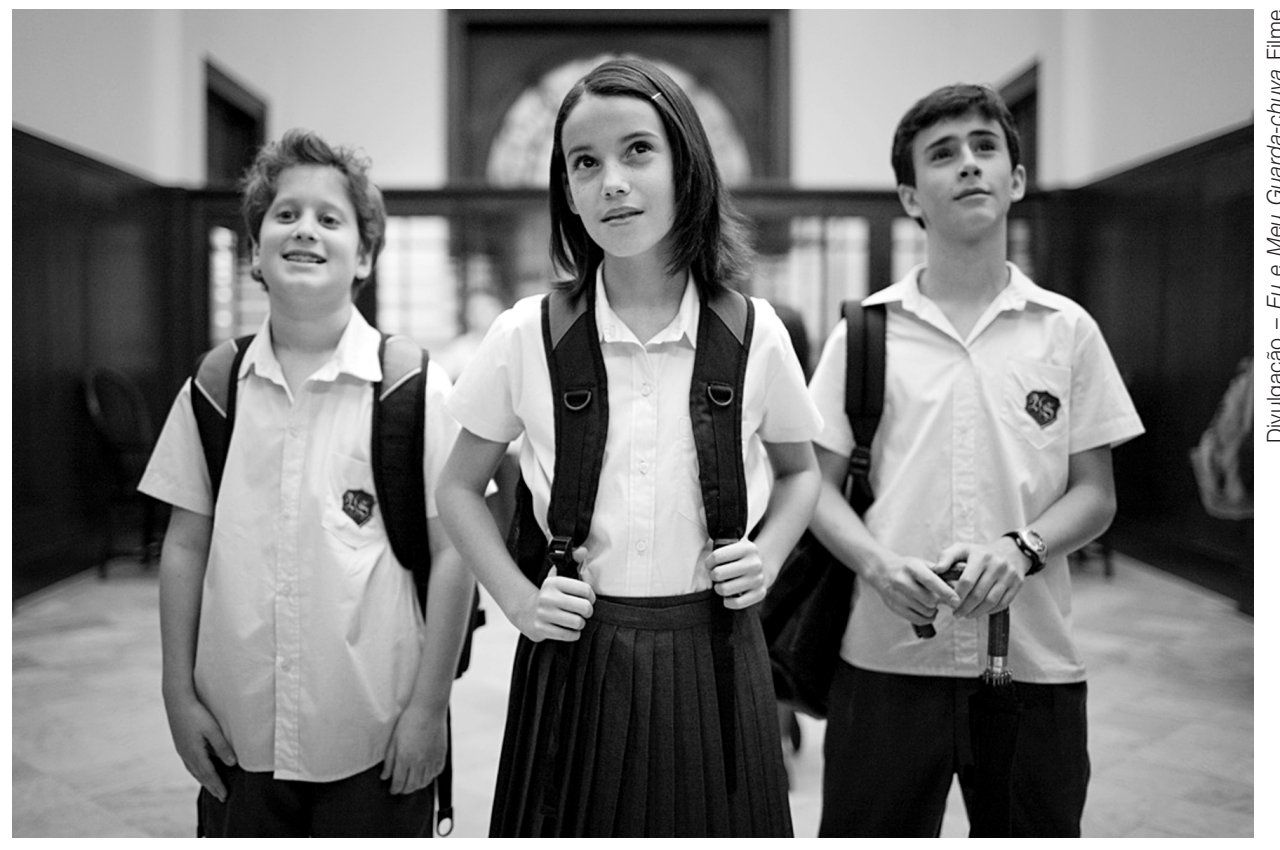

Cebola, Nina e Eugênio. 
Memórias de infância, amores, afetos. Da infância, uma das memórias é a da escola, que por ser um lugar de muitas histórias registra e deixa registrar muitos sentimentos, aventuras, medos, descobertas. Pensando nas afirmações e perguntas que o filme traz, na escola, porque também é feita de muitas afirmações e perguntas e, particularmente, no cinema como um meio que convida e favorece a imaginação e a construção de sensibilidades, acredito que o filme Eu e Meu Guarda-chuva possa ser utilizado como exercício com alunos do quinto ano do atual Ensino Fundamental, momento de passagem para o sexto ano, antiga quinta série, quando ocorre a mudança de ciclo. Quando a passagem é um rito, expectativa de aventuras, medo do desconhecido. Medo e expectativa do que virá e do vir a ser, mas também coragem de responder perguntas, de se declarar apaixonado, de perceber que temíveis fantasmas perguntadores podem ser derrotados quando se usa a imaginação e o conhecimento.

\section{QUANDO A AVENTURA PODE ESTAR NA POSSIBILIDADE DE CONHECER}

Na história do filme um dos lugares preferidos de Eugênio e Frida é o terraço do prédio onde moram. No banco olham estrelas, recitam as constelações, contam alguns dos seus segredos, projetam futuros. Uma das brincadeiras que o avô fazia com Eugênio era a de imaginar dez anos antes e dez anos depois. Como eram e como poderiam ser. O contrário também. No sonho-aventura de libertar Frida da sala de aula em que o Barão aprisionava as crianças e as submetia aos interrogatórios, Eugênio e Cebola trafegam entre São Paulo e Praga; viajam de trem e avião e, ao vivenciarem o dez anos para a frente e para trás, ensaiam as primeiras reflexões sobre tempo e espaço. Tempos, espaços, lugares, tudo misturado: os das crianças, dos autores, nossos, porque, afinal, somos feitos de memórias. Se Eugênio e Cebola, ao se deslocarem no metro, reencontram cenários possivelmente visitados em outros livros e histórias infantis; se algumas cenas lembram O Pequeno Príncipe ou Harry Porter, ou especificamente, quando estão no metrô em busca do guarda-chuva, onde todos os personagens são homens e idênticos, mesmo que nem todos usem um guarda-chuva, é impossível não lembrar os quadros de Magrite; se os mapas se movimentam, as pessoas falam línguas estranhas e se entendem; se sobre as mesas da classe estão enormes atlas geográficos e se as perguntas do Barão fantasma formam um rol de conhecimentos que as crianças aprenderão no novo ciclo escolar, uma pergunta aparece: aquelas perguntas todas feitas pelo fantasma torturador não poderiam transformar-se num grande jogo? Por que não aproveitar todas aquelas perguntas sem respostas e principiar um exercício sobre geografia, história, botânica e palavras, essencialmente sobre as palavras, porque no desconhecimento delas estava o problema de Cebola, o menino que, por não saber respostas de nada, matou o Barão do coração? 
Por que não transformar perguntas em um jogo de buscar respostas? Talvez na busca de conhecimentos esteja a chave para discutirmos ou entendermos afirmações como a de que existir é ser prisioneiro da terra; ou porque somos feitos de memória; ou quantas eram as naus de Pedro Álvares Cabral; o que foi a guilhotina, e ainda qual é o sujeito da frase: a flagrância das flores me agradam. Talvez, no universo surreal que o sonho permite e que a imaginação alimenta, possamos entender melhor o que acontece quando o cinema faz as palavras encontrarem as imagens e o duelo travado nas sombras entre Eugênio, seu guarda-chuva, e a espada do vilão que inicia a narrativa do filme mostre a mágica da vida. 